\title{
Reflecting on 40 Years of Graduate Medical Education in Family Medicine: Where Should the Future Lead Us? Reaction to the Paper by Perry A. Pugno, MD, MPH
}

\author{
Nikitas J. Zervanos, MD
}

I wish to applaud Perry for a well-thought out vision for the future of family medicine education. ${ }^{1}$ However, with all due respect, I am going to disagree on his proposal for a 4-year curriculum.

Although I retired from the directorship of our residency in 2002 and feel a bit out of the academic loop, I have emeritus status and still serve my patients in my 40-year-old, predominantly GreekAmerican practice and precept at our rural-based family practice center. As the currents of change swoop around me, I may be missing a beat or two, but I hope my argument will remain on target.

Let me begin by reflecting just a bit on our history. I have observed the future unfold as I witnessed the metamorphosis of general practice into family medicine. Remember, the shortage of physicians, especially in primary care, was a driving force for the creation of the new specialty. In 1960 we had fewer than 8000 allopathic and osteopathic school graduates, and $<10 \%$ of our medical students were choosing general practice as a career. In 1965, with the enactment of the Social Security Act Title XVIII (Medicare) and Social Security Act Title XIX (Medicaid) entitlement programs, the demand for medical and health care services escalated. In the meantime, many communities were without their general practitioner, and the need for primary care physicians reached a crisis.

After the establishment of our specialty in 1969 came new Title VII primary care initiatives, which facilitated the growth of family medicine and incentivized internal medicine and pediatrics to create primary care tracts as well as educational institutions to train new health practitioners. However,

From the Family Practice Residency Program, Lancaster General Hospital, Lancaster, Pennsylvania.

Funding: none.

Conflict of interest: none declared.

Corresponding author: Nikitas J. Zervanos, MD, 22 River Drive, Lancaster, PA 17603 (E-mail: njzervan@comcast.net). the demand for traditional specialists also intensified.

Although it has been 40 years since our specialty took root, the reasons for its inception and the arguments for why family medicine is so important have not changed. There was general agreement that we needed no less than $25 \%$ of the growing number of new graduates in family medicine. We then changed that to no less than $50 \%$ in primary care, to include family medicine, internal medicine, pediatrics, and even obstetrics and gynecology. Today, with $>22,000$ allopathic and osteopathic graduates, the family practice number should be exceeding 5,000 new trainees. We have never met our targets.

Times have changed and we have changed, and the need for more of us has grown. Few of us are in a solo practice (many more are in a group practice); more of us are employed and work fewer hours; many no longer practice fee for service; more of us want fixed hours of employment with more time available to be devoted to recreational and family activities; and more of us just want to work part time. In the meantime, lifestyles have improved and incomes have escalated and the new model of family medicine promises a more cost-effective patientcentered medical home.

Essentially, our specialty advocates first contact and personalized, continuous, coordinated, and comprehensive health care. Yet, as Perry points out, because of competing curriculum requirements, residents' time in the family practice center is curtailed and continuity is compromised. Expanding residency training to 4 years would allow more concentrated time in the family practice center and facilitate the continuity experience while enhancing teaching and scholarly opportunities.

However, I don't think this is necessary or even desirable for the following reasons: 
1. Residents maintain continuity with a sufficient number of their patients during 3 years.

2. The "team" concept within the patient-centered medical home is already in place and adds another level of continuity.

3. The integration of the electronic medical record has enhanced the coordination of preventive medical services.

4. Certificates of added qualifications in Geriatrics, Adolescent Medicine, Sports Medicine, Sleep Medicine, or Hospice and Palliative Medicine already add a fourth year and opportunities for customized education.

5. A certificate of added qualification in Maternity Care should be created and the requirements in obstetrics and gynecology should be revised to accommodate those residents who choose to deliver or not to deliver babies.

6. Teaching does occur and scholarly activity is required. I suggest it begin in the middle of the first year and completed by the middle of the third year.

7. Experience tells me that residents are ready to enter practice by the time they complete a 3 -year residency.
8. Finally, and perhaps most importantly, 4 years of residency training not only increases the cost of graduate medical education but it delays by one more year a needed family physician entering community practice, and hence accentuates the physician shortage.

Seven years have lapsed since I stepped down after 33 years as a program director, but I hope that does not make me a "fuddy-duddy" and that you will consider my apology to retain the 3 -year residency as apropos.

I want to thank Jim Puffer, Larry Green, and the Board of Family Medicine for the opportunity to share my thoughts with you.

\section{Reference}

1. Pugno PA. One giant leap for family medicine: preparing the 21 st-century physician to practice patientcentered, high-performance family medicine. J Am Board Fam Med 2010;23(Suppl):S23-7. 